\title{
EVALUATION OF ELISA TEST AS A RAPID SCREENING TOOL FOR DETECTION OF JOHNE'S DISEASE AMONG SUSPECTED SMALL RUMINANTS IN MAKKAH, KSA
}

\author{
GHADA A. ABOU EL-ELLA ${ }^{*, * *}$; IBRAHIM H.A. ABD EL-RAHIM ${ }^{* * * * * * * *}$ and OMAR B. AHMED ${ }^{* * *}$ \\ * Clinical Laboratory Diagnosis, Department of Animal Medicine, Faculty of Veterinary Medicine, Assiut University, 71526 \\ Assiut, Egypt. \\ *** Department of Laboratory Medicine, Faculty of Applied Medical Sciences, Umm Al-Qura University, KSA. \\ ${ }_{* * * *}^{*}$ Infectious Diseases, Department of. Animal Medicine, Faculty of Veterinary Medicine, Assiut University, Egypt. \\ **** Department of Environmental and Health Research, the Custodian of the Two Holly Mosques Institute for Hajj and \\ Umrah Research, Umm Al-Qura University, KSA.
}

Email: ghadaabou22@yahoo.com

Assiut University web-site: www.aun.edu.eg

ABSTRACT

Received at: 31/5/2015

Accepted: 4/7/2015
The present study aimed to utilize molecular tools to evaluate the reliability of IDEXX Paratuberculosis Screening ELISA versus traditional microscopic examination of acid fast-stained-fecal smear for rapid detection of Johne's disease among clinically suspected small ruminants in Makkah region, KSA. For this purpose, three different genetic targets, including $16 \mathrm{~S}$ rDNA, insertion sequence 900 (IS900) and intergenic spacer (IGS), were used for molecular detection and identification of MAP among suspected cases and was used as golden standard for the evaluation study. A total of 3490 small ruminant animals from five different farms around Makkah were clinically investigated for characteristic signs of JD during the period of November 2013 to June 2014. Out of investigated animals, 41 cases were selected as being suspected of JD infection based on the associated clinical symptoms (persistent diarrhea with emaciation). Fecal samples (including rectal swabs) and blood samples were collected from all suspected small ruminants. Fecal samples were subjected to both conventional microscopic examination and molecular examination. Blood samples were used for serum separation and conduction of immunologic assay using IDEXX Paratuberculosis Screening ELISA. The results showed that out of the 41 suspected cases, 14 (34.1\%) and $15(36.6 \%)$ cases were positive for JD using microscopic examination and ELISA, respectively. On the other hand molecular evaluation of JD infection among suspected cases revealed an initial infection rate of $43.9 \%$ based on the amplification of both bacterial 16SrDNA and Mycobacterium genus-specific IGS targets. However, further investigation of suspected samples by detection of MAP-specific IS900 and sequence analysis of the Mycobacterium species-specific IGS targets confirmed MAP infection among only $34.1 \%$ of the suspected cases. Using molecular results as a standard, higher sensitivity ( $85.7 \%$ vs. $50 \%)$, specificity ( $88.9 \%$ vs. $70.4 \%)$, PPV (80\% vs. $46.7 \%)$, NPV (92.3\% vs. $73.1 \%)$ and AI (87.8\% vs. $63.4 \%)$ were recorded for ELISA as compared to microscopic detection of AF bacilli in fecal smear, respectively. In conclusion the study revealed the feasibility of the IDEXX Paratuberculosis Screening ELISA as a reliable tool for rapid detection of Johne's diseases among suspected cases of small ruminants.

Keywords: Paratuberculosis, AF bacilli, IDEXX Paratuberculosis Screening ELISA, 16s rDNA, IGS, IS900.

\section{INTRODUCTION}

Johne's diseases (JD) or paratuberculosis (PTB) is a chronic, progressive enteric disease of ruminants caused by infection with Mycobacterium avium subsp. paratuberculosis (MAP). Paratuberculosis is a chronic infectious disease of cattle, small ruminants and wild ruminants, characterized by therapy- resistant diarrhea and weight loss. The spread of MAP could significantly hamper the livestock industry via its detrimental impact on animal health and the consequential loss in productivity (Clarke, 1997 and Richardson and More 2009).

Identification of infected animals and their eradication is the base for the disease control. 
Diagnosis of the disease depends on characteristic clinical signs confirmed by a wide range of diagnostic tests that categorized into those that identify the organism and those that identify an immunological reaction to the organism (Collins, 1994 and Sweeney et al., 1995).

During the course of the diseases, infection with MAP usually pass through 3 main stages depending on the severity of clinical signs, potential for shedding organisms into the environment, and the ease with which the disease may be detected by using current laboratory methods (Whitlock and Buergelt 1996). Silent infection is the first stage of infection that is characterized by absence of clinical signs of infection and absence of measurable subclinical effects of infection. Infected animals in this stage may shed infectious organisms into the farm environment at levels below the threshold of detection (De Lisle and Duncan 1981). During this stage, no costeffective diagnostic tests can detect the infection. The only means of detecting infected cattle at this early stage is by demonstration of the established organism in the intestinal tract, either by culture or by histologic demonstration of micro-granulomas in the intestine or regional lymph nodes. Other diagnostic tests, such as johnin (sterile solution of growth products of Johne's bacillus) skin testing and gammainterferon tests that utilize the cell-mediated response (CMI), have also been used to detect this stage of the disease. However, there are common antigens between MAP and other environmental Mycobacterium spp., resulting in low specificity (Sp) for these tests (Kalis et al., 2003 and McDonald et al., 1999), making them ineffective as routine screening tests. The second stage is the subclinical infection, where animals at this stage do not yet have clinical signs of infection, but may be detected as infected by using cost-effective diagnostic tests and may begin to have measurable effects of infection (Tiwari et al., 2003, Tiwari et al., 2005). Some of these infected animals may be detected by fecal culture. However, focal lesions, variable rates of disease progression and shedding, and dilution of organisms in large volumes of intestinal content result in intermittent detection of fecal shedding (Merkal and Thurston 1966). Therefore, other infected animals may test negative by using current fecal culture techniques. Some animals may have detectable antibodies to MAP, particularly if they are getting close to entering the next stage of the disease (clinical phase) (Kennely and Benedictus 2001). However, MAP fecal shedding usually occurs before detectable antibody response (Lepper et al., 1989). The clinical infection stage is the stage during which initial clinical signs following a prolonged incubation period start to appear. The first apparent sign is gradual weight loss, despite a normal appetite. Concurrent with the weight loss, the manure consistency becomes more fluid. The diarrhea may be persistent or intermittent, at first, with periods of normal manure consistency (Whitlock and Buergelt 1996). Most animals at this stage have a positive fecal culture and have increased serum antibody levels detectable by the commercial enzyme-linked immunosorbant assay (ELISA) and agar gel immunodiffusion (AGID) test (Kalis et al., 2004).

It can detect growth of MAP in multiple organs, including the intestinal mucosa and sub-mucosa, and regional lymph nodes (McKenna et al., 2004). However, tissue culture is not commonly used as a gold standard in many previous studies, due to the high cost and logistical difficulties of sampling for tissue culture (Milner et al., 1990; Sweeney et al., 1995 and Dargatz et al., 2001). Alternatively, fecal culture is more commonly used during comparative diagnostic studies as golden standard. Fecal culture can be applied to various species and sample types (feces, tissue, water, soil) during the clinical stage of the disease to confirm infection. However, some studies reported the unreliability of fecal culture in sheep and some other ruminant species when using standard laboratory techniques (Stich et al., 2004). In addition, it is labor intensive and may require 8-24 weeks of incubation for colonies to be observed based on the type of media used with a subsequent questionable sensitivity (Collines 1994; Whitlock and Buergelt 1996 and Stich et al., 2004).

In term of sensitivity of golden standard assays, recent studies have shown the superiority of PCRbased molecular assays over conventional culturing methods for sensitive and accurate detection of MAP infection among subclinical and clinical cases (Douarre et al., 2010). In this regard, Sequences of IS900 proved to be highly sensitive and specific markers of $M$. paratuberculosis among other slowly growing, acid-fast bacteria. IS900 has a unique nucleotide sequence which can be specifically detected by hybridization or PCR techniques. Previous studies showed that IS 900 has been detected in all reference and vaccine strains as well as in field isolates of $M$. paratuberculosis from several hosts but never in other bacterial species (Whipple et al., 1987; Green et al., 1989 and Moss et al., 1992). In addition, sequence- dependent identification has been shown to be an especially effective molecular tool that provides rapid and accurate differential identification of Mycobacterium species (Cloud et al., 2002 and Mohamed et al., 2005). Most molecular approaches have focused on the conserved $16 \mathrm{~S}$ small subunit ribosomal DNA (rDNA) sequence (Springer et al., 1996). However, the fact that the product of the 16S rDNA gene serves a vital function in the bacteria makes the frequency of permissible mutations in this gene inherently limited. This limitation results in the presence of identical or highly homogenous $16 \mathrm{~S}$ rDNA sequences among some of the Mycobacterium 
species, making the differentiation of some closely related species difficult (Kim et al., 1999; Mohamed et al., 2005 and Mohamed et al., 2009). Alternatively, sequence analysis of the intergenic spacer (IGS) between the small (16S) and large (23S) subunit rRNA genes has been successfully used to differentiate among closely related Mycobacterium species (Roth et al., 1998; Mohamed et al., 2004 and Mohamed et al., 2005). Which make it a good target for molecular-based detection and identification of MAP among sub-clinically and clinically affected animals.

In KSA, sheep and goats constitute an integral part of the animal population that are raised principally by private breeders due to their manageable size and feed requirements plus their ability to utilize lowgrade food and limited pasture areas (Al-Dughaym et al., 2001). In KSA, small ruminants are mainly used for meat production where is considered the favorite meat for daily meals, festivals and religious occasions. During pilgrimage season, hundreds of thousands of sheep and goats are sacrificed. This necessitates the importation of large quantities of sheep from various parts of the world, which could represent a source of infection to the Saudi herds (AlNaeem et al., 2000).

In small ruminants, JD is characterized by debilitation and emaciation that is unresponsive to de-wormers and antibiotics (Whitlock and Buergelt 1996). In spite of weight loss, the appetite is often good. The profuse watery diarrhea, seen in cattle, is not a common feature of the disease in sheep and goats, where normal stool is usual observation even in clinically diseased animals. However, intermittent diarrhea or softened, pasty stools are occasionally observed in small ruminants. In addition, intermittent, low-grade fever, inter-mandibular edema (bottle jaw), lethargy, and depression are sometimes seen (Manning and Collins 2001). The disease may be confused with intestinal parasitism, chronic malnutrition, caseous lymphadenitis (especially animals with internal abscesses), ovine progressive pneumonia (OPP), environmental toxins, and cancer (Manning and Collins 2001 and Collins 2003).

The aim of the present study is to evaluate one of the commercial Paratuberculosis screening ELISA (IDEXX PTB Screening) as a rapid tool for detection of JD among clinically suspected small ruminants in Makkah region in comparison with conventional microscopic detection of acid fast bacilli in fecal smears from suspected animals. Confirmation of infection by 3 different genetic targets (16S rDNA, IS900 and IGS) was conducted and used as golden standard for evaluation purposes.

\section{MATERIALS and METHODS}

\section{Clinical investigation and sampling:}

A total of 3490 local sheep (Naemy breed) were investigated in the current study for suspected signs of John's disease. The animals were investigated during the period of November 2013 to June 2014 and were belonged to Al-Kaakiah slaughterhouse (the main abattoir of Makkah) as well as five small ruminant farms around Makkah. Clinically suspected animals were selected and isolated based on history and clinical examination. Inclusion criteria included animals suffering from debilitation and emaciation that is unresponsive to de-wormers and antibiotics, intermittent diarrhea or softened, pasty stools, lowgrade fever, lethargy, and depression (Manning and Collins 2001). Fecal samples (including rectal swabs) were collected from clinically suspected animals. Preparation of the samples, fecal direct smears and molecular examination were carried out in the microbiology and molecular biology laboratories at the environmental and health research department, Hajj and Umrah Research Institute and the central research laboratories, Dept. Laboratory Medicine, Faculty of Applied Medical Sciences, Umm Al-Qura University, Makkah.

\section{Conventional Microscopic examination:}

Collected samples from clinically suspected cases were initially evaluated microscopically for expected acid fast bacilli. For this purpose direct smears were prepared from fecal specimens and rectal swaps that were stained with standard ZN stain as previously described (Quinn et al., 1994).

\section{ELISA}

M. paratuberculosis antibody test kit (IDEXX Laboratories, Inc., Westbrook, Maine) was used to test sera from all suspected animals according to the manufacturer's instructions. With this kit, optical density (OD) values were transformed to $\mathrm{S} / \mathrm{P}$ ratios based on the OD for the serum sample together with those for the negative and positive controls provided with the kit by using the following equation: S/P ratio (OD of sample OD of negative control)/(OD of positive control OD of negative control). All assays were run in duplicate. Any assay with a between-well coefficient of variation of $10 \%$ was repeated, and the second result was used for data analysis (HumaReader HS, Human Gesellschaft fur Biochemica, Wiesbaden, Germany).

\section{Molecular detection and identification:}

DNA extraction from fecal specimens. DNA was extracted from collected specimens of all suspected animals as previously described (Bollet et al., 1991) using Promega Genomic Wizard DNA Purification Kit (Promega, Madison, WI, USA), with some 
modification. Briefly, the fecal material was diluted in PBS and homogenized with easyMIX® Lab Blender (AES Chemunex, Bruz Cedex, France) in filter bags (Seward, Thetford, Norfolk, UK). Pellets were washed with $1 \mathrm{ml}$ of TE (10 mM Tris, $\mathrm{pH} 8,10$ mM EDTA) and were resuspended in $100 \mu \mathrm{l}$ of TE. After addition of $50 \mu \mathrm{l}$ of $10 \%$ SDS the mixture was incubated for $30 \mathrm{~min}$ at $65^{\circ} \mathrm{C}$. The lysates were centrifuged and supernatants were removed. The microtubes were then placed in a microwave oven (with specifications; LG grill, model No. MG-604AZ, input $220 \mathrm{v}-50 / \mathrm{bHz}$, microwave $1350 \mathrm{w}$, RF output $900 \mathrm{w}, 2,4500 \mathrm{MH}$ ) and heated twice for $1 \mathrm{~min}$ at 900 $\mathrm{W}$ or three times for $1 \mathrm{~min}$ at $750 \mathrm{~W}$. The pellets were dissolved in $200 \mu \mathrm{l}$ of TE and were extracted with an equal volume of phenol/chloroform/ isoamyl alcohol (25:24:1) for $15 \mathrm{~min}$. The aqueous phase was recovered by centrifugation for $20 \mathrm{~min}$ and precipitated with ethanol.

Amplification of selected genomic targets. Three genomic targets were amplified from DNA obtained from all suspected animals' specimens. This included $16 \mathrm{~S}$ rDNA, IGS and IS900. The hypervariable 500 bp. segment of the 16S rDNA was amplified using the previously described universal bacterial primer set (Hall et al., 2003). In addition, the hypervariable region of the intergenic spacer (IGS) target was amplified from suspected samples using the previously described pan-Mycobacterium primer set ITS-A1 and ITS-A6 (Mohamed et al., 2005). Finally, the MAP-specific IS900 target was amplified using primer set P90 (5_GAAGGGTGTTCGGGGCCGTC) and P91 (5_ GAGGTCGATCGCCCACGTGAC) as previously described by Khare et al., (2004). All primer sets were obtained from IDT Integrated DNA technologies (IDT, Belgium).

In the PCR assay, $5 \mu \mathrm{l}$ of template DNA $(10 \mathrm{ng} / \mu \mathrm{l})$ in a total reaction volume of $50 \mu$ l to include PCR buffer $[20 \mathrm{mmol}$ Tris-HCL (pH 8.4) and $50 \mathrm{mmol}$ $\mathrm{KCl}$ ], $0.1 \mathrm{mmol}$ each of dNTP (deoxyribonucleotide triphosphate), $1.5 \mathrm{mmol}$ of $\mathrm{MgCl} 2,0.3 \mu \mathrm{mol}$ of each primer, and 1.5 U of RED Taq DNA polymerase were used. The PCR amplification was performed in a Techne thermocycler model TC-312 starting with an initial denaturation step at $95^{\circ} \mathrm{C}$ for $10 \mathrm{~min}$, followed by 35 cycles where each cycle consisted of a denaturation at $95^{\circ} \mathrm{C}$ for $1 \mathrm{~min}$, an annealing at $64^{\circ} \mathrm{C}$ for $30 \mathrm{sec}$, and an extension step at $72^{\circ} \mathrm{C}$ for $1 \mathrm{~min}$. After PCR, $10 \mu \mathrm{l}$ of the PCR product was mixed with $5 \mu \mathrm{l}$ dye mixture $(0.25 \%$ bromophenol blue and $0.25 \%$ xylene cyanol in $15 \%$ Ficoll type 400 ) and electrophoresed in $1 \mu \mathrm{l}$ Tris-acetate-EDTA buffer through a $1 \%$ agarose gel containing ethidium bromide $(0.5 \mu \mathrm{g} / \mathrm{mL})$. Bands of the appropriate size were visualized using a UVP gel documentation system according to the manufacturer's instructions and identified by comparison with a 100-bp DNA ladder (DNA molecular weight marker Promega).

IGS sequence analysis. Purified IGS products from all IGS-positive samples were sequenced using the same IGS-amplification primer set at the Molecular Biology Core Laboratory, Egyptian Institute for Biological Products and Vaccine Production (Cairo, Egypt). Obtained sequences were analyzed using both the custom MycoAlign database (Mohamed et al., 2005) and BLAST (Basic Local Alignment Search Tool; http://www.ncbi.nlm.nih.gov/BLAST/).

\section{RESULTS}

Obtaining of history and clinical examination of the 3490 investigated animals resulted in selection of 41 animals with suspected symptoms of John's disease. Selected animals showed symptoms ranged from debilitation and emaciation that is unresponsive to antibiotics or deworming anti-parasitic drugs, softened stools or diarrhea, fever to depression and separation from the flocks. Initial microscopic screening of $\mathrm{ZN}$-stained direct smears from fecal samples and rectal swaps from all suspected cases, showed that 14 out of the suspected 41 cases (34.1\%) were positive for acid-fast bacilli (Figure 1). The results of the ELISA-based serological testing for detection of antibodies against MAP in the serum samples of suspected sheep indicated that 15 (36.6\%) out of 41 suspected sheep sera were seropositive.

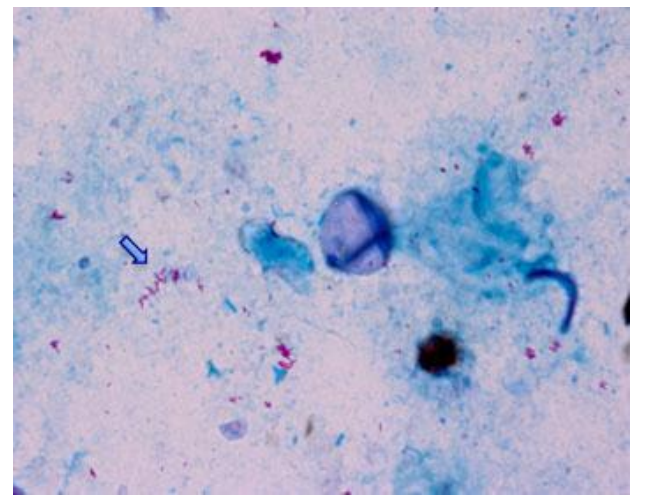

Figure 1: ZN-stained direct fecal smear showing aggregation of acid fast short bacilli (arrow) 
On the other hand, molecular-based detection and identification assays revealed an initial detection of 26 $(63.4 \%)$ positive cases based on the detection and amplification of bacterial-specific 16S rDNA target (Figure 2).

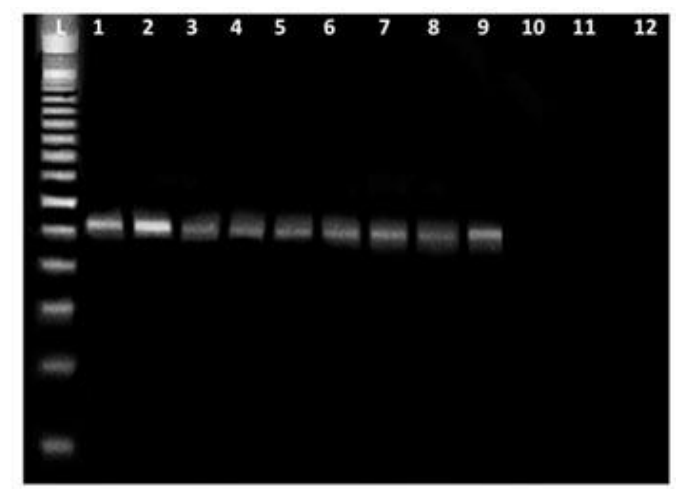

Figure 2: Representative 1\% agarose gel showing the amplification of the universal bacterial target $16 \mathrm{~S}$ rDNA. Lane (L) 100 pb. DNA ladder. Lanes 1-9 showing $500 \mathrm{bp}$. product of 16S rDNA target from suspected animals. Lanes 10-11 showing negative results for the universal bacterial target. Lane 12, negative control showing no $16 \mathrm{~S}$ product.

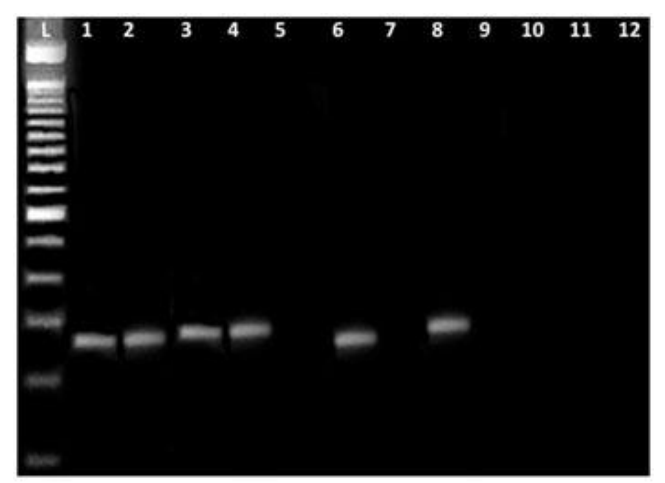

Figure 3: Representative 1\% agarose gel showing the amplification of Mycobacterium genus-specific IGS target using pan-Mycobacterium primers. Lane (L), 100 pb. DNA ladder. Lane 1, 2, 3, 4, 6 and 8 showing positive product of Mycobacterium-specific IGS target (280-300 bp.) from suspected animals. Lanes 5, 7, 9, 10 and 11 showing negative product of Mycobacterium-specific IGS target. Lane 12, negative control showing no IGS product.

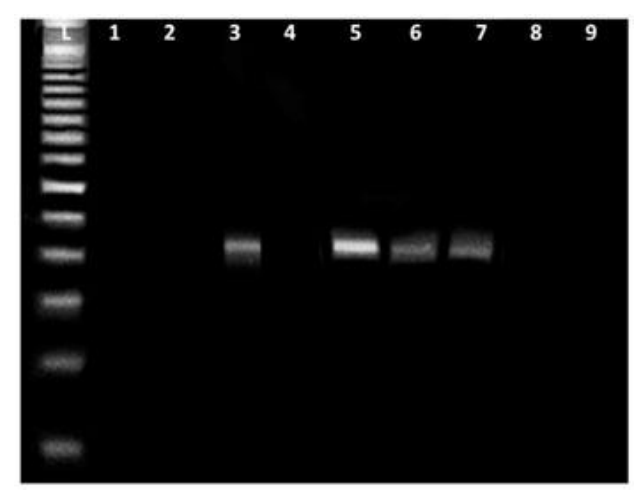

Figure 4: Representative 1\% agarose gel showing the amplification of the Mycobacterium avium subspecies paratuberculosis-specific IS900 target. Lane (L), 100 pb. DNA ladder. Lanes 1, 2, 4 and 8 showing negative product of IS900 target. Lanes 3, 5, 6 and 7 showing positive IS900 target (400 bp.) from suspected animals. Lane 9, negative control showing no product. 
Out of these $16 \mathrm{~S}$ rDNA-positive samples, only 18 $(43.9 \%)$ cases were confirmed as Mycobacterium species using the Mycobacterium genus-specific IGS primers (Figure 3). Further investigation of the selected 18 samples with confirmed Mycobacterium species infection using both sequence analysis of obtained IGS target amplicons as well as amplification of the MAP-specific IS900 targets (Figure 4) has confirmed the presence of Mycobacterium avium subspecies paratuberculosis in only $14(34.1 \%)$ samples (Table 1$)$.

Evaluation of ELISA versus conventional microscopic examination.

The final results of the molecular detection and identification assays were used as a golden standard for the evaluation study of ELISA test versus the conventional microscopic assay (Table 2). The evaluation study revealed that out of the 14 and 15 positive cases detected by the conventional microscopic assay and ELISA test, respectively, 7 and 12 cases were considered true positive while 7 and 3 cases were considered false negative by the 2 tests, respectively. On the other hand, out of the negative results by the conventional microscopic assay and ELISA test, 19 and 24 cases were considered true negative while 7 and 2 cases were considered false negative, respectively (Table 3 ). Based on these findings, the evaluation study revealed higher SN (85.7\%), SP (88.9\%), PPV (80\%), NPV $(92.3 \%)$ and AI $(87.8 \%)$ of the IDEXX paratuberculosis screening ELISA assay as compared to that $(50 \%, 76 \%, 50 \% 76 \%$ and $60.9 \%$, respectively) of the conventional microscopic examination assay of $\mathrm{ZN}$-stained smears of fecal samples and rectal swaps (Table 3 ).

Table 1: Results of different diagnostic methods for detection of Cryptosporidium from suspected patients' stool specimens.

\begin{tabular}{|c|c|c|c|c|c|c|c|c|c|c|c|c|}
\hline \multirow{6}{*}{$\begin{array}{c}\text { Clinically } \\
\text { suspected } \\
\text { animals } \\
(41)\end{array}$} & \multicolumn{12}{|c|}{ Diagnostic assays } \\
\hline & \multirow{3}{*}{\multicolumn{2}{|c|}{$\begin{array}{c}\text { Mic. } \\
\text { Examination }\end{array}$}} & \multirow{3}{*}{\multicolumn{2}{|c|}{$\begin{array}{c}\text { ELISA } \\
\text { examination }\end{array}$}} & \multicolumn{8}{|c|}{ Molecular assays } \\
\hline & & & & & \multicolumn{6}{|c|}{ Target detection } & \multirow{2}{*}{\multicolumn{2}{|c|}{$\frac{\text { Target sequencing }}{\text { IGS }}$}} \\
\hline & & & & & \multicolumn{2}{|c|}{$16 \mathrm{~S}$} & \multicolumn{2}{|c|}{ IGS } & \multicolumn{2}{|c|}{ IS900 } & & \\
\hline & no. & $\%$ & no. & $\%$ & no. & $\%$ & no. & $\%$ & no. & $\%$ & no. & $\%$ \\
\hline & 14 & 34.1 & 15 & 36.6 & 26 & 63.4 & 18 & 43.9 & 14 & 34.1 & 14 & 34.1 \\
\hline
\end{tabular}

Table 2: Matching cross tabulation of CS-PCR assay as gold standard assays and the other evaluated diagnostic assay.

\begin{tabular}{cccc}
\hline Diagnostic assays & \multicolumn{2}{c}{ ITS/IS900 ID of MAP } & \multirow{2}{*}{ Total } \\
\cline { 2 - 4 } & Positive results & Negative results & \\
\hline $\begin{array}{c}\text { Mic +ve } \\
\text { Elis. +ve }\end{array}$ & 5 & 2 & 7 \\
\hline $\begin{array}{c}\text { Mic +ve } \\
\text { Elis. -ve }\end{array}$ & 2 & 5 & 7 \\
\hline $\begin{array}{c}\text { Mic -ve } \\
\text { Elis. +ve }\end{array}$ & 7 & 1 & 19 \\
\hline $\begin{array}{c}\text { Mic -ve } \\
\text { Elis. -ve }\end{array}$ & 0 & 19 & 41 \\
\hline Total & 14 & 27 & 7 \\
\hline
\end{tabular}

Table3: Evaluation of MZN-AF, CA-RT and CAD-ELISA as compared to CS-PCR as gold standard assay for detection of Cryptosporidium in stool specimens.

\begin{tabular}{ccccccccccc}
\hline \multirow{2}{*}{ Evaluated assays } & \multicolumn{4}{c}{ Obtained results \% } & \multicolumn{3}{c}{ Evaluation parameters \% } \\
\cline { 2 - 10 } & TP & FN & TN & FP & SN & SP & PPV & NPV & AI \\
\hline Mic. & 7 & 7 & 19 & 7 & 50 & 76 & 50 & 76 & 60.9 \\
\hline ELISA & 12 & 2 & 24 & 3 & 85.7 & 88.9 & 80 & 92.3 & 87.8 \\
\hline
\end{tabular}




\section{DISCUSSION}

Diagnosis of PTB depends on clinical signs confirmed by microscopic demonstration of $M$. paratuberculosis in the feces, culture, or by the use of DNA probes and the PCR. Diagnosis of subclinical infection depends on the detection of specific antibodies by serology, or culture of $\mathrm{M}$. paratuberculosis from feces or tissues collected at necropsy, or the demonstration of cell-mediated response through the use of the gamma interferon assay. The choice of test depends on the circumstances and the degree of sensitivity required at individual animal or herd level (WOAH, 2008). Currently, available tests to detect infected animals produce many false-negative results and some falsepositives, particularly in sub-clinically infected animals, thus making their interpretation and utilization challenging in control programs (Tiwari et. al., 2006). As the disease represent a great problem among ruminant animals in Saudi Arabia and due to its zoonotic possibility, this study aimed to implement genetic tools to evaluate IDEXX-PTB Screening assay, as one of the commercial Paratuberculosis screening ELISA, in comparison with conventional microscopic detection of acid fast bacilli in fecal specimens as a rapid tool for detection of JD among clinically suspected animals. For this purpose confirmation of infection was achieved molecularly using 3 different genetic targets (16S rDNA, IS900 and IGS), which results were used as golden standard for the evaluation study.

In the current study, 3 different genetic elements were used as targets for gold standard assays for diagnosis of MAP, including IS900, $16 \mathrm{~S}$ rDNA and IGS. IS900 represents one of the most prominent targets used in several studies to detect DNA of $M$. avium subsp. paratuberculosis by PCR $(19,21)$. The multi-copy (17 copies) nature of the sequence on the M. avium subsp. paratuberculosis chromosome makes it ideal as a target sequence for the detection of $M$. avium subsp. paratuberculosis, since it exhibits a higher level of sensitivity compared to the use of single-copy genes as targets (Li et al., 2005 and Soumya et al., 2009). However, the specificity of target IS 900 is not $100 \%$, since IS900 insertion elements with close sequence homology are also present on the chromosomes of $M$. cookii, M. mari- num, $M$. paraffinicum, and M. scrofulaceum isolates (Cousins et al., 1999; Englund et al., 2002; Kim et al., 2002 and Semret et al., 2006). Furthermore, polymorphisms detected in IS900 as variants of $M$. avium subsp. paratuberculosis have been previously described; such variants should be interpreted as suggestive of the presence of a Mycobacterium organism other than $M$. avium subsp. paratuberculosis until the detection has been confirmed by independent methods (Rajeev et al.,
2005). Therefore, the current study used additional genetic target for the confirmation of the presence or absence of the infection. Recently, sequencedependent identification was introduced as an effective molecular tool that allows for precise and accurate identification of different Mycobacterium species (Cloud et al., 2002 and Mohamed et al., 2005). 16S rDNA sequence used to be the target of choice for differential identification of Mycobacterium species (Springer et al., 1996). However, limitations derived by the lack of permissible mutations in this gene, which serves a vital function in the bacteria resulted in the presence of identical or highly homogenous $16 \mathrm{~S}$ rDNA sequences among several Mycobacterium species and or strains, making the differentiation of some closely related species difficult (Kim et al., 1999; Mohamed et al., 2005 and Mohamed et al., 2009). Alternatively, IGS target that represent a hypervariable region of the Mycobacterium genome, allowed for precise differential identification between closely related Mycobacterium species (Mohamed et al., 2004; Mohamed et al., 2005 and Roth et al., 1998). Therefore, in order to ensure the reliability of geneticbased tools to serve as a golden standard for the current evaluation study, 3 different genetic targets were used for 3 levels-based identification of MAP and detection of JD among suspected animals. In the first step, amplification of $16 \mathrm{~S}$ rDNA sequence using universal bacterial primers allowed for detection of any possible bacterial causative agent among suspected animals. The second step was applied on selected positive cases using amplification of IGS target using pan0mycobacterial-specific primers to detect all possible Mycobacterium species. Finally the third step implemented both the detection of the MAP-specific IS900 target and sequence analysis of the obtained IGS sequences to ensure the presence of Mycobacterium avium subspecies paratuberculosis as the causative agent of JD among suspected animals.

Comparing ELISA with conventional microscopic assay, the current results revealed relatively higher sensitivity $(85.7 \%$ vs. $50 \%)$, specificity $(88.9 \%$ vs. $70.4 \%)$, PPV (80\% vs. $46.7 \%)$, NPV (92.3\% vs. $73.1 \%)$ and AI $(87.8 \%$ vs. $63.4 \%)$ of ELISA as compared to conventional microscopic detection of AF bacilli in fecal smear, respectively. Although $\mathrm{ZN}$ staining is the most rapid and cost-effective screening method, it lacks the required sensitivity; therefore, additional tests of suspected cases is required (Springer et al., 1996). Moreover, The intermittent shedding of the microorganism in the feces might results in cases that show negative results at conventional fecal smear microscopic examination, while seropositive at ELISA testing (Whitlock and Buergelt 1996). The poor sensitivity of conventional examination of AF-stained fecal swaps and/or fecal specimens as compared to ELISA was expected and 
attributed to the false negativity results in animals which shed at a very low level, therefore a greater number of low level shedders may be missed. In addition, the acid-fast microscopic detection assay have a lagging ability to distinguish between $M$. paratuberculosis in clumps or within epithelial cells from isolated nonpathogenic acid-fast rods commonly found in feces. This could explain the currently recorded lower specificity of the conventional microscopic assay as compared to ELISA (Tiwari et al., 2006).

Relatively high sensitivity of ELISA (85.7\%) in detection of JD among clinically suspected animals was recorded in the current study. Most of previous studies had evaluated ELISA as a screening test for JD among sub-clinically infected animals. A previous study recorded $7 \%$ sensitivity of ELISA in serum of animals in the silent stage, $15 \%$ in the subclinical stage, and between $85 \%$ to $98 \%$ in the clinical stage (Gilarddoni et al., 2012). Moreover, variable sensitivities ranged between 45-65\% were recorded for IDEXX-ELISA in detection of JD among subclinically infected animals (Milner et al., 1990; Ridge et al., 1991; Sockett et al., 1992; Sweeney et al., 1995 and Whitlock et al., 2000). The significantly lower sensitivity of IDEXX-ELISA among subclinical cases as compared to the currently recorded one among suspected clinical cases could be attributed to the fact that cell-mediated immunity is the dominant immune response, during the sub-clincal phase of the disease whereas; humoral immune response prevails at the clinical phase (Coussens, 2001 and ValentinWeigand, 2002). Humoral antibodies developed against the infection are primarily detected by ELISA (Vannuffel et al., 1994 and Manning and Collins 2001). Previous studies recorded that sensitivity of ELISA is only $15 \%$ in animals shedding low quantities of the causative agent with their feces, compared with $87 \%$ in animals with clinical signs (Sweeney et al., 1995). The delays in immune response or shedding also mean that when tests are utilized on animals with clinical JD, they will have a better Se than when they are used on animals with subclinical JD (Sweeney et al., 1995 and Whitlock et al., 2000), because the clinically affected animals are much more likely to be shedding bacteria or have developed a detectable immune response (Chiodini et al., 1984).

Although, the currently recorded specificity of ELISA (88.9\%) was relatively high as compared to conventional microscopic examination of AF-stained fecal smear $(76 \%)$, higher specificity $(98.9-99.8 \%)$ of the absorbed ELISA were recorded in diagnosis of JD among sub-clinically infected animals (Ridge et al., 1991). However, these results were based on serum samples from animals with three or more negative fecal cultures, The fact that some of these animals could have been infected at a low level that remained undetectable with three serial fecal cultures recommended that calculations of ELISA specificity should be based only on confirmed negative animals best obtained from repeated test negative herds (Collins and Sockett, 1993; Sockett et al., 1992), or alternatively using valid standard test that provide high sensitivity and specificity (Whitlock et al., 2000).

In conclusion, development of and search for new diagnostic tests require critical comparison of methodology. Serological diagnosis that relies on the specificity of antigen and the titer of antibodies represents a good option for rapid and accurate diagnosis of JD. The currently reported overall sensitivity $(85.7 \%)$ and specificity $(88.9 \%)$ of the IDEXX Paratuberculosis Screening ELISA in relationship to the precise PCR findings as a standard for evaluation, reveal the feasibility of IDEXXELISA as a reliable diagnostic assay. Coupled with the low cost and high-throughput capability inherent in ELISA technology, IDEXX-ELISA offers the best testing option for rapid detection of JD among clinical cases, which would support control programs of JD among commercial small ruminant herds in KSA.

\section{REFERENCES}

Al-Dughaym, A.M.; Fadl El mula, A.; Mohamed, G.E.; Hegazy, A.A.; Radwan, Y.A.; Housawi, F.T.M. and Gameel, A.A. (2001): First report of an outbreak of ovine septicaemic listeriosis in Saudi Arabia. Rev. sci. tech. Off.int. Epiz, 20: 777-783.

Al-Naeem, A.; Abu Elzein, E.M.E. and Al-Afale, A.I. (2000): Epizootiological aspects of peste des petits ruminants and rinderpest in sheep and goats in Saudi Arabia. Rev. sci. tech. Off. int. Epiz., 19 (3): 855-858.

Bollet, C.; Gevaudan, M.J.; Lamballerie, X.; Zandotti, C. and Micco, P. (1991): A simple method for the isolation of chromosomal DNA from Gram positive or acid-fast bacteria. Nucleic Acids Res 19: 1955-1956.

Chiodini, R.J.; Van Kruiningen, H.J. and Merkal, R.S. (1984): Ruminant paratubercu- losis (Johne's disease): the current status and future prospects. Cornell Vet., 74: 218-262.

Clarke, C.J. (1997): The pathology and pathogenesis of paratuberculosis in ruminants and other species. Journal of Comparative Pathology, 116: 217-261.

Cloud, J.L.; Neal, H.; Rosenberry, R.; Turenne, C.; Jama, M.; Hillyard, D. and Carroll, K. (2002): Identification of Mycobacterium spp. by using a commercial $16 \mathrm{~S}$ ribosomal DNA sequencing kit and additional sequencing libraries. J Clin Microbiol 40: 400-406.

Collins, M.T. (2003): Update on paratuberculosis: 1. 
Epidemiology of Johne's disease and the biology of Mycobacterium paratubertulosis. Irish Vet J., 56: 565-574.

Collins, M.T. (1994): Clinical approach to control of bovine paratuberculosis. J. Am. Vet. Med. Assoc., 204: 208-210.

Collins, M.T.; Sockett, D.C. and Ridge, S.E. (1993): Evaluation of a commercial enzyme-linked immunosorbent assay for Johne's disease. J. Clin. Microbiol. 5: 52-55.

Cousins, D.V.; Whittington, R.; Marsh, I.; Masters, A.; Evans, R.J. and Kluver, P. (1999): Mycobacteria distinct from Mycobacterium avium subsp. paratuberculosis isolated from the faeces of ruminants possess IS900- like sequences detectable IS900 polymerase chain reaction: implications for diagnosis. Mol. Cell Probes 13: 431-442.

Coussens, P.M. (2001): Mycobacterium paratuberculosis and the bovine immune system. Anim. Health Res., 2 (2001), pp. 141-161

Dargatz, D.A.; Byrum, B.A.; Barber, L.K.; Sweeney, R.W.; Whitlock, R.H.; Shulaw, W.P.; Jacobson, R.H. and Stabel, J.R. (2001): Evaluation of a commercial ELISA for diagnosis of paratuberculosis in cattle. J. Am Vet. Med. Assoc 2001; 218: 1163-1166.

De Lisle, G.W. and Duncan, J.R. (1981): Bovine paratuberculosis III. An evaluation of a whole blood lymphocyte transformation test. Can. J. Comp. Med. 45: 304-309.

Douarre, P.E.; Cashman, W.; Buckley, J.; Coffey, A. and Mahony J.M.O. (2010): Isolation and detection of Mycobacterium avium subsp. paratuberculosis (MAP) from cattle in Ireland using both traditional culture and molecular based methods. Gut Pathogens, 2: 11.

Englund, S.; Bolske, G. and Johansson, K.E. (2002): An IS900-like sequence found in a Mycobacterium sp. other than Mycobacterium avium subsp. para- tuberculosis. FEMS Microbiol. Lett. 209: 267-271.

Gilarddoni, L.R.; Paolicchi, F.A. and Mundo, S.L. (2012): Bovine paratuberculosis: a review of the advantages and disadvantages of different diagnostic tests. Revista Argentina de Microbiología 44: 201-215.

Green, E.P.; Tizard, M.L.V.; Moss, M.T.; Thomson, J.; Winterborne, D.J.; McFadden, J.J. and Hermon-Taylor, J. (1989): Sequence and characteristics of IS900, an insertion element identified in a human Crohn's disease isolate of Mycobacterium paratuberculosis. Nucleic Acids Res., 17: 9063-9073.

Hall, L.; Doerr, K.A.; Wohlfiel, S.L. and Roberts, G.D. (2003): Evaluation of the MicroSeq system for identification of mycobacteria by $16 \mathrm{~S}$ ribosomal DNA sequencing and its integration into a routine clinical mycobacteriology laboratory. J. Clin. Microbiol., 41: 1447-1453.

Kalis, C.H.; Collins, M.T.; Barkema, H.W. and Hesselink, J.W. (2004): Certification of herds as free of Mycobacterium paratuberculosis infection: actual pooled faecal results versus certification model predictions. Prev. Vet. Med., 65: 189-204.

Kalis, C.H.; Collins, M.T.; Hesselink, J.W. and Barkema, H.W. (2003): Specificity of two tests for the early diagnosis of bovine paratuberculosis based on cell- mediated immunity: the Johnin skin test and the gamma interferon assay. Vet. Microbiol, 97: 73-86.

Kennedy, D.J. and Benedictus, G. (2001): Control of Mycobacterium avium subsp. paratuberculosis infection in agricultural species. Rev. Sci. Tech., 20: 151-179.

Khare, S.; Ficht, T.A.; Santos, R.L.; Romano, J.; Ficht, A.R.; Zhang, S.; Grant, I.R.; Libal, M.; Hunter, D. and Adams, L.G. (2004): Rapid and sensitive detection of Mycobacterium avium subsp. paratuberculosis in Bovine Milk and Feces by a Combination of Immunomagnetic Bead SeparationConventional PCR and Real-Time PCR J. Clin. Microbiol. 42(3): 1075-1081.

Kim, B.J.; Lee, S.H. and Lyu, M.A. (1999): Identification of mycobac- terial species by comparative sequence analysis of the RNA polymerase gene (rpoB). J. Clin. Microbiol., 37: 1714-1720.

Kim, S.G.; Shin, S.J.; Jacobson, R.H.; Miller, L.J.; Harpending, P.R.; Stehman, S.M.; Rossiter, C.A. and Lein, D.A. (2002): Development and application of quantitative poly- merase chain reaction assay based on the ABI 7700 system (TaqMan) for detection and quantification of Mycobacterium avium subsp. paratuberculosis. J. Vet. Diagn. Invest., 14: 126-131.

Lepper, A.W.; Wilks, C.R.; Kotiw, M.; Whitehead, J.T. and Swart, K.S. (1989): Sequential bacteriological observations in relation to cellmediated and humoral antibody responses of cattle infected with Mycobacterium paratuberculosis and maintained on normal or high iron intake. Aust. Vet. J., 66: 50-55.

Li, L.; Bannantine, J.P.; Zhang, Q.; Amonsin, A.; May, B.J.; Alt, D.; Banerji, N.; Kanjilal, S. and Kapur, V. (2005): The complete genome sequence of Mycobacterium avium subspecies paratuberculosis. Proc. Natl. Acad. Sci. U. S. A. 102: 12344-12349.

Manning, E.J. and Collins, M.T. (2001): Mycobacterium avium subsp. paratuberculosis: pathogen, pathogenesis and diagnosis. Rev. Sci. Tech., 20: 133-150. 
McDonald, W.L.; Ridge, S.E.; Hope, A.F. and Condron, R.J. (1999): Evaluation of diagnostic tests for Johne's disease in young cattle. Aust. Vet. J., 77: 113-119.

McKenna, S.L.; Keefe, G.P.; Barkema, H.W.; McClure, J.; Vanleeuwen, J.A.; Hanna, P.; and Sockett, D.C. (2004): Cow-level prevalence of paratuberculosis in culled dairy cows in Atlantic Canada and Maine. J. Dairy Sci; 87: 3770-3777.

Merkal, R.S. and Thurston, J.R. (1966): Comparison of Mycobacterium paratuber- culosis and other mycobacteria, using standard cytochemical tests. Am. J. Vet. Res., 27: 519-521.

Milner, A.R.; Mack, W.N.; Coates, K.J.; Hill, J.; Gill, I. and Sheldrick, P. (1990): The sensitivity and specificity of a modified ELISA for the diagno- sis of Johne's disease from a field trial in cattle. Vet. Microbiol., 25: 193-198.

Mohamed, A.M.; Kuyper, D.J.; Iwen, P.C.; Ali, H.; Bastola, D.R. and Hinrichs, S.H. (2005): Computational approach involving use of the internal transcribed spacer-1 region for identification of Mycobacterium species. J. Clin. Microbiol., 43: 3811-3817.

Mohamed, A.M.; Abou El-Ella, G.A. and Nasr, E.A. (2009): Phenotypic and molecular typing of tuberculous and nontuberculous Mycobacterium species from slaughtered pigs in Egypt J. Vet. Diagn. Invest., 21: 48-52.

Mohamed, A.M.; Iwen, P.C.; Tarantolo, S. and Hinrichs, S.H. (2004): Mycobacterium nebraskiae sp. nov., a new slow-growing scotochromogenic Mycobacterium. Int J. Syst. Evol. Microbiol., 54: 2057-2060.

Moss, M.T.; Sanderson, J.D.; Tizard, M.L.V.; Hermon-Taylor, J.; El-Zaatari, F.A.K.; Markesich, D.C. and Graham, D.Y. (1992): Polymerase chain reaction detection of Mycobacterium paratuberculosis and Mycobacterium avium subsp. silvaticum in long term cultures from Crohn's disease and control tissues. Gut., 33: 1209-1213.

Quinn, P.J.; Markey, B.K.; Carter, M.E.; Donelly, W.J.C. and Leonard, F.C. (1994): Veterinary microbiology and microbial diseases. $1^{\text {st }}$ edition, Iowa State University Press Blackwell Science.

Rajeev, S.; Zhang, Y.; Sreevatsan, S.; Motiwala, A.S. and Byrum, B. (2005): Evaluation of multiple genomic targets for identification and confirmation of Mycobacterium avium subsp. paratuberculosis isolates using real-time PCR. Vet. Microbiol., 105: 215-221.

Richardson, E.K.B. and More, S.J. (2009): Direct and indirect effects of Johne's disease on farm and animal productivity in an Irish dairy herd. Ir. Vet. J. 62(8): 526-532.
Ridge, S.E.; Morgan, I.R.; Sockett, D.C.; Collins, M.T.; Condron, R.I.; Skilbeck, N.W. and Webber, J.J. (1991): Comparison of the Johne's absorbed EIA and the complementfixation test for the diagnosis of Johne's disease in cattle. Australian Veterinary Journal., 68(8): 253-257.

Roth, A.; Fischer, M.; Hamid, M.E.; Michalke, S.; Ludwig, W. and Mauch, H. (1998): Differentiation of phylogenetically related slowly growing mycobacteria based on $16 \mathrm{~S}$ 23S rRNA gene internal transcribed spacer sequences. J. Clin. Microbiol., 36: 139-147.

Semret, M.; Turenne, C.Y. and Behr, M.A. (2006): Insertion sequence IS900 revisited. J. Clin. Microbiol., 44: 1081-1083.

Sockett, D.C.; Carr, D.J. and Collins, M.T. (1992): Evaluation of conventional and radiometric fecal culture and a commercial DNA probe for diagnosis of Mycobacterium paratuberculosis infections in cattle. Canadian Journal of Veterinary Research 56(2): 148-153

Soumya, M.P.; Pillai, R.M.; Antony, P.X.; Mukhopadhyay, H.K. and Rao, V.N. (2009): Comparison of faecal culture and IS900 PCR assay for the detection of Mycobacterium avium subsp. paratuberculosis in bovine faecal samples. Vet. Res. Commun. 33: 781-791.

Springer, B.; Stockman, L.; Teschner, K.; Roberts, G.D. and Böttger, E.C. (1996): Two laboratory collaborative study on identification of mycobacteria: molecular versus phenotypic methods. J. Clin. Microbiol., 34: 296-303.

Stich, R.W.; Byrum, B.; Love, B.; Theus, N.; Barber, L. and Shulaw, W.P. (2004): Evaluation of an automated system for non-radiometric detection of Mycobacterium avium paratuberculosis in bovine feces. J. Microbiol. Methods., 56: 267-275.

Sweeney, R.W.; Whitlock, R.H.; Buckley, C.L. and Spencer, P.A. (1995): Evaluation of a commercial enzyme-linked immunosorbent assay for the diagnosis of paratuberculosis in dairy cattle. J. Vet. Diagn. Invest., 7: 488-493.

Tiwari, A.; Vanleeuwen, J.A.; Dohoo, I.R.; Stryhn, H. and Keefe, G.P. (2003): Effects of seropositivity for bovine leukemia virus, Mycobacterium avium subspecies paratuberculosis, and Neospora caninum on calving to conception interval in maritime Canadian dairy cattle. Proc. Soc. Vet. Epidemiol. Prev. Med, Warwick, England., 243-252.

Tiwari, A.; VanLeeuwen, J.A.; Dohoo, I.R.; Stryhn, H.; Keefe, G.P. and Haddad, J.P. (2005): Effects of seropositivity for bovine leukemia virus, bovine viral diarrhoea virus, Mycobacterium avium subspecies paratuberculosis, and Neospora caninum on 
culling in dairy cattle in four Canadian provinces. Vet. Microbiol., 109: 147-158.

Tiwari, A.; VanLeeuwen, J.A.; McKenna, S.L.B.; Keefe, G.P. and Barkema, H.W. (2006): Johne's disease in Canada: Part I: Clinical symptoms, pathophysiology, diagnosis, and prevalence in dairy herds. Can Vet $\mathrm{J}, 47$ : 874-882.

Valentin-Weigand, $\quad P$. (2002): John's disease: pathogenesis and problems related to diagnosis. In: Kaske, M., Scholz, H., Holtershinken, M. (Eds.), Recent Developments and Perspectives in Bovine Medicine. XXII World Buiatrics Congress, Hanover, Germany., 48-57.

Vannuffel, P.; Gilot, B.; Limbourg, B.; Naerhuyzen, B.; Dieterich, C.; Coene, M.; Machtelinckx, L. and Cocito, C. (1994): Developement of a species-speci®c enzyme-linked immunosorbent assay for diagnosis of Johne`s disease in cattle. J. Clin. Microbiol., 32:
1211-1216.

Whipple, D.L.; Le Febvre, R.B.; Andrews, R.E.; Jr., and Thiermann, A.B. (1987): Isolation and analysis of restriction endonuclease digestive patterns of chromosomal DNA from Mycobacterium paratuberculosis and other Myco- bacterium species. J. Clin. Microbiol., 25: 1511-1515.

Whitlock, R.H.; Wells, S.J.; Sweeney, R.W. and Van Tiem, J. (2000): ELISA and fecal culture for paratuberculosis (Johne's disease): sensitivity and specificity of each method. Vet. Microbiol., 77: 387-398.

Whitlock, R.H. and Buergelt, C. (1996): Preclinical and clinical manifestations of paratuberculosis (including pathology). Vet. Clin. North. Am. Food Anim Pract., 12: 345-356.

World Organization for Animal Health (OIE) (2008): Paratuberculosis. OIE Terrestrial Manual., http://www.oie.int/Eng/normes/ MMANUAL/ 2008/pdf/2.04.14.pdf.

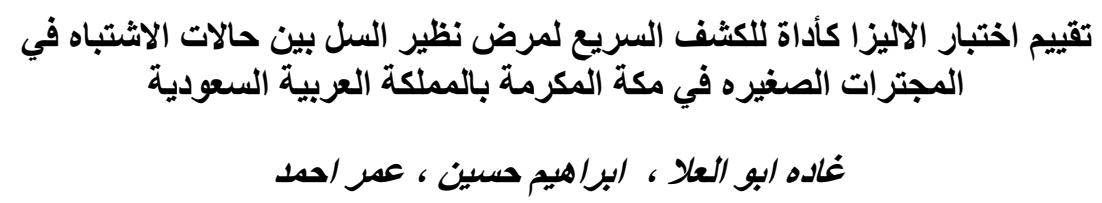

Email: ghadaabou22@yahoo.com

Assiut University web-site: $\underline{w w w . a u n} . e d u . e g$

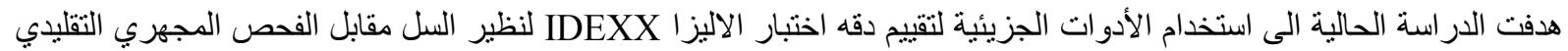

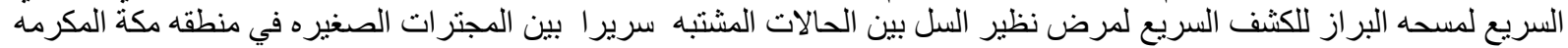

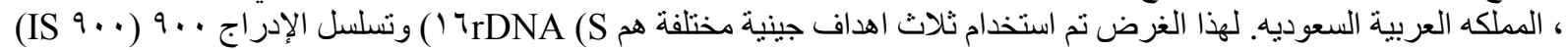

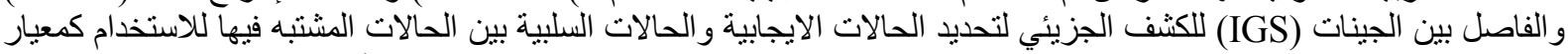

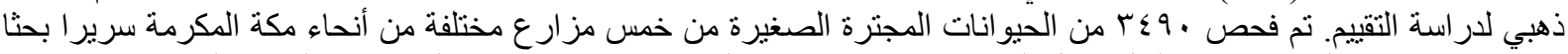

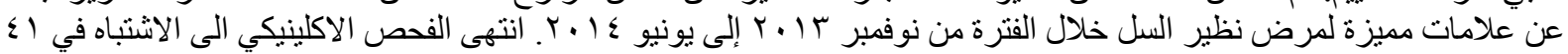

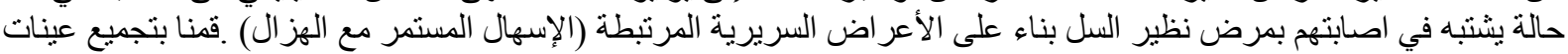

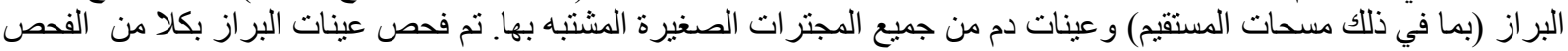

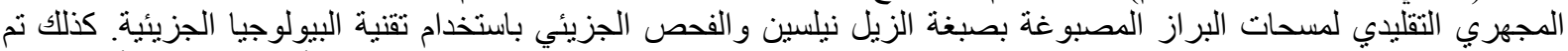

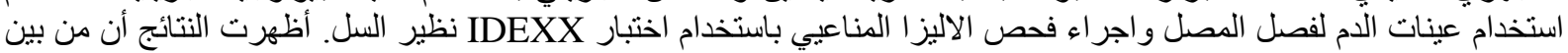

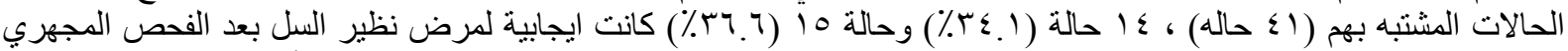

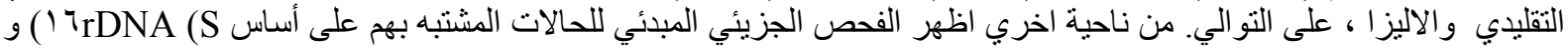

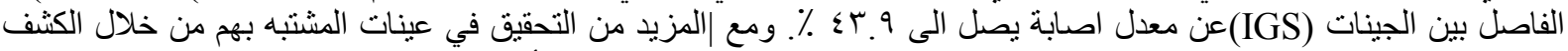

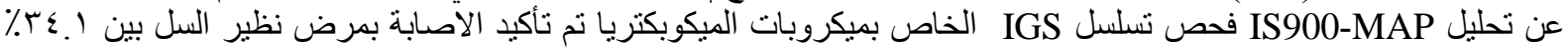

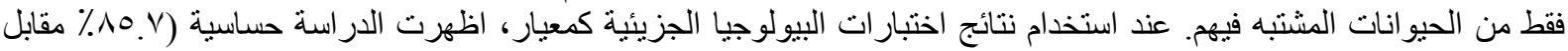

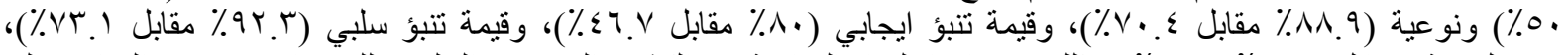

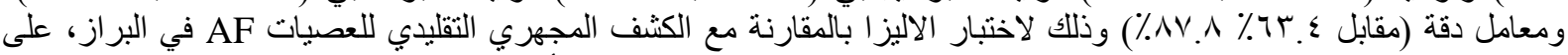

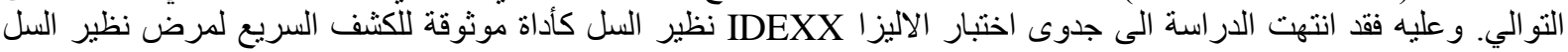

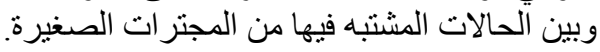

